\title{
A escalada neoconservadora e a agenda antigênero: o caso da participação do Brasil na Cúpula Demográfica de Budapeste
}

\author{
Felipe Furini Soares ${ }^{*}$ \\ Arlene Martinez Ricoldi ${ }^{\star *}$
}

\begin{abstract}
Este artigo busca analisar o significado da participação do Brasil na III Cúpula Demográfica de Budapeste. Esse encontro é derivado de uma série de eventos que ocorrem desde 2015, a partir da ascensão do governo de extrema-direita de Viktor Orbán. Com o objetivo de pensar o enfrentamento ao declínio populacional, a partir de estratégias anti-imigração e pró-família, o evento vem se posicionando como um contraponto às conferências da ONU. Enquanto percurso metodológico, partimos de pesquisa on-line e documental no site dos organizadores da cúpula e do governo brasileiro para, posteriormente, utilizarmos a análise crítica do discurso (ACD) para o pronunciamento da ministra Damares Alves durante o evento, com reflexão a partir dos estudos feministas pós-estruturalistas. 0 que se apura é uma inflexão do Brasil à agenda neoconservadora e antigênero, se associando a países de extrema-direita, fundamentalistas e contrários à defesa de direitos humanos. 0 discurso proferido instrumentaliza noções demográficas para camuflar suas perspectivas ideológicas em relação ao gênero, emprestando ares de discurso científico aos ataques aos direitos sexuais e reprodutivos e às noções de família não tradicionais.
\end{abstract}

Palavras-chave: Gênero. Família. Demografia. Cúpula de Budapeste. Governo Bolsonaro.

\footnotetext{
* Universidade Federal do ABC (UFABC), São Bernardo do Campo-SP, Brasil (felipefurini@gmail.com; https://orcid.org/00000002-7997-5550).

** Universidade Federal do ABC (UFABC), São Bernardo do Campo-SP, Brasil (arlene.ricoldi@ufabc.edu.br; https://orcid. org/0000-0002-2330-7633).
} 


\section{Introdução}

O objetivo deste artigo é analisar a participação do Brasil na Conferência Demográfica de Budapeste e seu significado em relação às posições brasileiras em espaços transnacionais de discussão a respeito de direitos humanos, em especial aqueles que se debruçam sobre questões de gênero, família e população. Essa participação, somente pela sua existência, reflete e sintetiza a posição do governo do presidente Jair Bolsonaro a respeito dessas temáticas.

Foi a partir dos dias 5 e 6 de setembro de 2019 que a opinião pública brasileira passou a conhecer, com algum destaque, a Cúpula Demográfica de Budapeste, já em sua terceira edição. ${ }^{1} 0$ evento, que nas duas primeiras edições havia passado, em grande medida, despercebido, ganhou as manchetes com a participação da ministra da Mulher, da Família e dos Direitos Humanos (MMFDH), Damares Alves.

De acordo com os organizadores da cúpula, ${ }^{2}$ a questão demográfica se apresenta como central para pensar o futuro de algumas nações, sobretudo aquelas que sofrem do encolhimento e envelhecimento populacional. Nesse sentido, essa série de eventos busca, a priori, discutir formas de pôr fim ao declínio populacional, a partir de estratégias pró-família, incentivo à reprodução e restrição à imigração de estrangeiros.

Desde a sua criação, a Organização das Nações Unidas (ONU) tem tido compromisso com estudos populacionais, lançando mão da estratégia de amplos debates em âmbito mundial. As Conferências Internacionais de População e Desenvolvimento (CIPD) são espaços de discussão que articulam desenvolvimento econômico e crescimento populacional, com reuniões que cobrem mais de 50 anos de história (Roma, 1954; Belgrado, 1965; Bucareste, 1974; México, 1984; Cairo, 1994 e Nairobi, 2019).

Dessa forma, o presente artigo examina a participação do Brasil na III Cúpula Demográfica de Budapeste, suas origens, seus idealizadores, pautas e os agentes sociais que integraram as discussões, com o objetivo de refletir sobre a participação de autoridades do Estado brasileiro naquele encontro. Interessa especificamente, neste trabalho, analisar o significado da presença do Brasil nesse espaço de discussão anti-imigração e pró-família, de sua posição institucional que integra um processo transnacional de reorganização de gênero ${ }^{3}$ da ordem social, típica de sociedades com arranjos reprodutivistas, isto é, voltadas à preservação e ao incentivo à família cis-heteronormativa.

Nesse sentido, compreender o significado de engajar-se no evento, que não constitui um espaço transnacional oficial (isto é, fora do sistema ONU), é importante para melhor entender como o governo Bolsonaro posiciona-se e rompe com as posturas mantidas pelas

\footnotetext{
$\overline{1}$ I Cúpula realizada em 2015 e a II Cúpula em 2017.

2 Página oficial da III Cúpula Demográfica de Budapeste, disponível em: https://bdselsoacsalad.hu/en/policy. Acesso em: 15 jan. 2020.

${ }^{3}$ Apesar das diversas noções de gênero em disputa na literatura, aqui se está mobilizando particularmente a noção clássica de Scott (1994, p. 13), de que "gênero é a organização social da diferença sexual".
} 
gestões anteriores, desde a redemocratização. Para isso, optamos por focar no discurso proferido pela representante do governo. ${ }^{4}$

0 artigo está dividido em cinco partes. A primeira traz uma contextualização da participação brasileira em espaços transnacionais para discussão de direitos humanos, nos quais gênero tornou-se um tema transversal e ubíquo. Na segunda, procura-se demonstrar o significado da organização da Cúpula Demográfica de Budapeste, pelo governo de extrema-direita de Viktor Orbán. Posteriormente é analisada a atuação do Ministério da Mulher, da Família e dos Direitos Humanos do governo de Bolsonaro e são abordados os aspectos teórico-metodológicos que orientam a análise. Por fim, nos debruçamos no discurso realizado na cúpula.

\section{A participação brasileira nos espaços transnacionais de direitos humanos}

As últimas décadas, sobretudo a partir dos anos 1990, foram cruciais para os estudos culturais e de gênero e sua consolidação como campos científicos. Na arena internacional, observou-se o avanço do debate sobre direitos humanos com a consolidação de diretrizes que incluíram também os direitos sexuais e reprodutivos.

Segundo Martins (2019), a forte incidência do movimento feminista na redemocratização do Brasil, aliado com a internacionalização da sociedade civil, garantiu ao país atuação determinante nas conferências. A partir dos anos 1990, o Brasil passou a realizar reuniões preparatórias, de modo que os documentos oficiais brasileiros obtivessem contribuições da sociedade civil e da academia. A partir da CIPD do Cairo, o país passou a credenciar representantes da sociedade civil na delegação brasileira, garantindo ao longo de 25 anos a participação majoritária de mulheres atuantes em políticas de saúde, a partir dos eixos de gênero, sexualidade e reprodução.

De acordo com Berquó (2014), Cairo representou uma ruptura na maneira como "populações" vinham sendo tratadas nas conferências. Pela primeira vez, as discussões sobre reprodução humana e planejamento familiar colocaram em primeiro plano a condição das mulheres. 0 entendimento sobre saúde foi ampliado e abrangeu a saúde reprodutiva, incorporando as dimensões física, mental e social, no sentido de pensar uma vida sexual digna, segura e satisfatória. Esse novo entendimento passou a vigorar nas demais conferências e debates nos espaços transnacionais no âmbito das Nações Unidas. A delegação brasileira, de acordo com Martins (2019), constituiu ativamente o esforço para ampliação desse entendimento, a partir da participação da sociedade civil e da academia na delegação brasileira.

A Década da Mulher é outro marco de discussões internacionais, que contou com três conferências mundiais sobre a mulher (Cidade do México, 1975; Copenhague, 1980; Nairóbi, 1985). Da terceira, resultou um importante documento, que orientou os debates

\footnotetext{
${ }^{4}$ Como se verá adiante, a ministra Damares assinala que o discurso foi elaborado para ser pronunciado pelo próprio Bolsonaro, que acabou por não participar do evento inicialmente programado.
} 
subsequentes. Além das conferências citadas, a década de 1990 produziu uma série de documentos que se tornaram a base para as discussões de direitos humanos. Todos os documentos abordam a questão das desigualdades de gênero, com particular ênfase nas Conferências da Mulher ${ }^{5}$ (Beijing, 1995) e sobre População ${ }^{6}$ (Cairo, 1994), mas também sobre Meio Ambiente e Desenvolvimento (Rio de Janeiro, 1992) (BRUSCHINI; RICOLDI, 2008).

Com o avanço das discussões sobre gênero e sua pauta progressista (em relação aos direitos reprodutivos e à agenda feminista para a questão), outros atores se organizaram no campo oposto; esforços já há algumas décadas protagonizados pelo Vaticano, com apoio de diversos países que explicitamente recusavam a igualdade de gênero. ${ }^{7} \mathrm{Na}$ Rio 92 , os ataques da Santa Sé e seus aliados foram no sentido de evitar uma discussão sobre planejamento familiar e direitos reprodutivos, sob o discurso de ser um controle populacional do Norte contra o Sul. Na CIPD do Cairo, atuaram pelo não reconhecimento do aborto como tema de saúde pública e sobre as diversas formas de família. Já em Beijing, buscaram vincular gênero a uma discussão que partisse do sexo biológico, tinham restrições em incorporar direito das mulheres como direitos humanos, evitaram rever a legislação punitiva para o aborto, além da aversão com relação à educação sexual das meninas, aos direitos sexuais das mulheres e às nomenclaturas para orientação sexual (CORREA, 2018).

Assim, em razão das conferências da década de 1990 e início dos anos 2000, o Vaticano e seus aliados começaram a se articular em uma política antigênero (CORREA, 2018). De acordo com Junqueira (2018), a retórica antigênero se ramifica em diversas frentes, desde suspensão da discussão de gênero e sexualidade na educação, limitação de informação sobre saúde sexual para adolescentes, embate contra os arranjos familiares não heteronormativos, retorno da estratégia de patologização das homossexualidades e transgeneridade, até outros ataques que impactam diretamente na garantia de direitos e possibilidades de existências.

Para Machado (2017), os movimentos pró-família ou ainda pró-vida, tal como se autodenominam, são articulações neoconservadoras instauradas tanto a partir de agentes religiosos como pela via legislativa. Sua narrativa irá se fundamentar em três dimensões: religiosa, que universaliza um entendimento religioso a partir de perspectiva cristã; jurídica, que parte do direito absoluto da vida, em detrimento do direito da mulher, e em razão de sua função dentro do modelo de família tradicional; e científica, que singulariza a vida a partir da descoberta genética do DNA e a vincula com a alma, concebendo assim um indivíduo "corpo e alma".

Em relação à atuação das delegações brasileiras nas conferências, Sardenberg (2018) destaca que, mesmo em meio às duras negociações com setores fundamentalistas ao

\footnotetext{
${ }^{5}$ Impulsionado pelas redes de mulheres lésbicas internacionais, uma discussão sobre direitos sexuais, para tratar justamente sobre sexualidade.

${ }^{6}$ Sobretudo pela inclusão no documento oficial sobre direito ao planejamento familiar e saúde reprodutiva (CORREA, 2018).

${ }^{7}$ Scott (1995), revisando a potencialidade crítica do conceito de gênero, aponta como exemplo justamente a oposição que o termo vinha sofrendo na esfera internacional.
} 
longo dos anos, o governo brasileiro sustentava as posições progressistas construídas coletivamente com o movimento feminista. Isso garantiu ao movimento brasileiro maior integração com outros países nos espaços transnacionais, além de se pensar de maneira regionalizada e interseccional. Notoriamente, à medida que o conservadorismo avançava, cabia ao movimento feminista maior pressão e monitoramento por parte das ações do governo brasileiro. ${ }^{8}$

\section{Cúpula Demográfica de Budapeste e o atual governo húngaro}

A denominação Cúpula de Demografia de Budapeste, em um primeiro momento, pode levar a pensar que se trata de eventos da natureza, como os que foram apresentados na seção anterior. No entanto, apesar da discussão e do formato da cúpula, estes encontros não só acontecem fora do Sistema ONU, como também buscam ser um contraponto.

Trata-se de um evento promovido pelo governo de Viktor Orbán, um dos representantes mais paradigmáticos da guinada à extrema-direita entre os países da Europa. Já na sua terceira edição, vem angariando crescente apoio entre as lideranças mundiais que se identificam com sua linha política. Com base nos registros dos expositores da cúpula, verificou-se a fala de 29 lideranças políticas ( 4 chefes de Estado, ${ }^{9} 12$ ministros ${ }^{10}$ e 13 representantes do legislativo ${ }^{11}$ ), 5 religiosos, 13 representantes de organizações da sociedade civil e 2 cientistas.

0 evento teve como objetivo fazer frente a quatro questões: a mudança na estrutura familiar; a redução do crescimento populacional; o envelhecimento da população; e o aumento dos movimentos migratórios.

Mesmo como um espaço que se move por fora dos organismos e mecanismos oficiais de negociação internacional, a participação e o envolvimento de autoridades públicas nacionais ampliam a influência deste espaço e suas pautas. Para que se possa ter um melhor entendimento do contexto e do momento histórico que o evento se insere, é fundamental trazer alguns elementos sobre a conjuntura política da Hungria, a partir do final dos anos 2000.

De acordo com Aries (2019), integrante da rede de jornalistas independentes GroundThruth, o atual primeiro-ministro da Hungria, Orbán, foi o fundador do partido Fidesz de centro-direita, após a queda da União Soviética. Ao longo do tempo, depois de ser eleito primeiro-ministro em 1998, 2010 e 2018, fez uma condução política de crescente extremismo à direita, tratando de posicionar o pensamento liberal europeu como uma ameaça, o que o tornou uma liderança autocrática, porém, eleito via sistema democrático.

\footnotetext{
${ }^{8}$ De acordo com Nagamine, em matéria de Rodrigues (2019), a atual posição do governo Bolsonaro estabelece uma inflexão na trajetória brasileira após mais de 20 anos no debate multilateral de gênero.

${ }^{9}$ Presidente da Sérvia, da República Checa, primeiro-ministro da Austrália e Hungria.

${ }^{10}$ Ministros de diferentes pastas, oriundos dos governos do Brasil, Bangladesh, Cabo Verde, Estados Unidos, Hungria, País Basco (Espanha), Polônia e Letônia.

${ }^{11}$ Deputados e parlamentares da Alemanha, Austrália, Bulgária, Estados Unidos, Gana, Hungria e Polônia.
} 
A partir de 2010, o governo Orbán promoveu uma nova Constituição, com fortes restrições à atuação de organizações não governamentais e limitações a partidos políticos de oposição, além de induzir uma série de articulações para controle midiático, realizado por empresários alinhados ao governo.

Na discussão sobre a moralidade pública, Orbán tratou de associar cada vez mais “o bom cidadão húngaro" aos cristãos conservadores. As ideias progressistas foram sendo classificadas como interferências externas indesejadas, com pretensão a desestabilizar o governo nacional (ARIES, 2019).

A política internacional de Orbán se concentra no enfrentamento da imigração, no combate ao terrorismo e a na defesa de cristãos $^{12}$ que possam estar sob algum tipo de ameaça. Ferreira (2016) ressalta que os intensos fluxos migratórios no Mediterrâneo a partir de 2015 estabelecem um marco para uma crise humanitária, que coloca em xeque valores fundantes da União Europeia de salvaguardar direitos humanos. Nesse contexto, a experiência da Hungria é paradigmática, uma vez que implementou uma política nacional de portas fechadas contra imigrantes. 0 modelo húngaro contraria uma série de determinações da UE, chegando a permitir o acionamento do Exército para proteção de fronteiras, a utilização de aparatos letais contra imigrantes, além de construir muros e bloqueios de fronteira para inibir a imigração. Em 2018, o Parlamento Europeu aprovou punição histórica ${ }^{13}$ à Hungria por ignorar regras democráticas.

Esse programa político de extrema-direita também inclui uma forte agenda antigênero. Segundo Biroli (2020), em 2018 foi firmado um decreto que proibiu os estudos de gênero nas universidades nacionais. Além da censura, tal ataque às questões de gênero representa a estratégia central pela qual o governo húngaro tem atacado elites globais e construído uma identidade nacionalista. Dessa forma, a Hungria é o caso mais contundente do neoconservadorismo como forma de restrição democrática e elevação do autoritarismo na Europa.

0 avanço do neoliberalismo e das resistências às agendas de igualdade de gênero e diversidade sexual mundo afora, sobretudo a partir da última década do século XX, constitui o neoconservadorismo, que pode ser definido como:

[...] aliança entre atores diversos; juridificação dos conflitos políticos de caráter moral; desenvolvimento em contexto liberal-democrático, mas participando, no início do século, de processos iliberais e de erosão das democracias; caráter transnacional; e a relação com o neoliberalismo, sobretudo na perspectiva da responsabilização das famílias em meio a processo amplos de privatização e mercantilização. (BIROLI, 2020, p. 40)

\footnotetext{
12 Esta tônica também tem sido adotada pelo governo Bolsonaro. O secretário de Assuntos de Soberania Nacional e Cidadania do Itamaraty, Fábio Mendes Marzano, apoiou a cruzada em defesa do cristianismo no mundo, em seminário sobre perseguição cristã em Budapeste, realizado em 28 de novembro de 2019. Disponível em: https://oglobo.globo.com/mundo/ religiao-faz-parte-do-processo-de-reformulacao-das-politicas-publicas-no-brasil-afirma-diplomata-na-hungria-24107083. Acesso em: 10 fev. 2020.

13 Disponivel em: https://brasil.elpais.com/brasil/2018/09/12/internacional/1536751556_675046.html. Acesso em: 10 fev. 2020.
} 
Pode-se defini-lo também como um processo multidimensional que prevê ampla aliança entre diferentes setores, para legislar uma regulação moral da sexualidade, de perspectiva naturalista e reprodutivista, que acontece a partir de contextos democráticos e coloca em marcha a erosão da própria democracia, firmando a família como unidade privada de responsabilidades socialmente hierarquizadas, em meio ao desmonte de direitos sociais (BIROLI, 2020).

\section{Família, neoconservadorismo e agenda antigênero no governo Bolsonaro}

O governo Bolsonaro tem uma posição abertamente à direita, podendo ser identificado com a extrema-direita em muitos aspectos. Não é de se espantar, portanto, a aproximação com a Hungria de Orbán. De acordo com a cronologia das relações bilaterais entre Brasil e Hungria, disponibilizadas pelo Itamaraty, ${ }^{14}$ ao longo de 90 anos de reconhecimento diplomático, novembro de 2019 marcou a primeira visita de um chanceler brasileiro (no caso, Ernesto Araújo) àquele país. Cobertura jornalística de Chade (2019) apurou ainda que, no mesmo ano, outras seis visitas de alto escalão ${ }^{15}$ entre os governos foram realizadas, contando inclusive com a visita do deputado federal Eduardo Bolsonaro, ou seja, uma aproximação sem precedentes nas relações entre Brasil e Hungria. 0 governo de Orbán chegou a propor ao governo de Bolsonaro que o Brasil financiasse apoio às comunidades cristãs que estivessem sob ameaça no Oriente Médio (CHADE, 2019).

Analisando documentos eclesiásticos e textos religiosos e laicos, Junqueira (2018) demonstra como esse projeto de poder instaura um cenário político discursivo, no qual setores ultraconservadores católicos e cristãos, aliados a diferentes forças políticas, engajam-se numa retórica antigênero, inclusive, criando a expressão "ideologia de gênero". ${ }^{16}$ Tal movimento vincula-se a um processo de rebiologização das questões de gênero como um contraponto ao que representa os avanços em estudos culturais, isto é, a "produção e a ativação de práticas e representações sobre a totalidade da vida e do mundo" utilizando-se de:

[...] estratégias discursivas [que] orientam-se não apenas a contrastar concepções desnaturalizantes de humanidade, corpo, gênero e sexualidade, mas sobretudo a promover a rebiologização da diferença sexual, a renaturalização das arbitrariedades da

\footnotetext{
$\overline{14}$ Disponível em: http://www.itamaraty.gov.br/pt-BR/ficha-pais/5225-hungria. Acesso em: 15 fev. 2020.

${ }^{15}$ Vale destacar a visita ao Brasil do ministro de Negócios Estrangeiros da Hungria, em 8 de outubro de 2019, que, em uma Comissão Mista Econômica, reafirmou: identidade nacional como direito humano fundamental; que questões globais não podem impor políticas nacionais; e que a proteção do meio ambiente depende das necessidades de desenvolvimento de cada país. Comunicado conjunto Brasil-Hungria sobre a visita oficial, disponível em: http://www.itamaraty.gov.br/pt-BR/ notas-a-imprensa/20967-comunicado-conjunto-brasil-hungria-visita-oficial-do-ministro-dos-negocios-estrangeiros-ecomercio-exterior-da-hungria-peter-szijjarto-brasilia-8-de-outubro-de-2019. Acesso em 01 fev. 2020.

${ }^{16} 0$ sintagma "ideologia de gênero" é apresentado entre aspas ao longo do manuscrito para demarcar uma posição política, a partir do uso de um conceito que não é validado em âmbito acadêmico. Como bem nos informa Junqueira (2018), em uma perspectiva sociológica, a "ideologia de gênero" se aplicaria à desnaturalização das relações de gênero, ao passo que o atual se enquadra dentro da campanha antigênero, que utiliza uma inversão discursiva para justamente reforçar a própria ideologia, manifesta no sistema cisheternormativo machista.
} 
ordem social, moral e sexual tradicional, a (re)hierarquização das diferenças e a afirmação restritiva, (hetero)sexista e transfóbica das normas de gênero (JUNQUEIRA, 2018, p. 486).

Muito da pauta conservadora em relação a família e gênero vem sendo colocada em movimento pelo Ministério da Mulher, da Família e dos Direitos Humanos. A própria redefinição da pasta, incluindo o termo família, dá o tom sobre o direcionamento do novo ministério ${ }^{17}$ - encabeçado pela advogada, educadora, pastora evangélica da Igreja do Evangelho Quadrangular, “mestre em educação, direito constitucional e direito da família” $(\operatorname{sic})^{18}$ Damares Alves, desde sua criação, no início do governo Bolsonaro, em 2 de janeiro de 2019, após ter ocupado o cargo de assessora do senador Magno Malta desde 2015.

A grande marca da gestão do governo Bolsonaro é o enfoque dado à família, sendo este colocado como um princípio norteador das políticas públicas. Com base na Medida Provisória n. 870/2019, de 1ํ de janeiro de 2019, posteriormente, Lei n. 13.844 de 18 de junho 2019, que reorganiza as competências dos ministérios, foi destinado ao Ministério da Mulher, da Família e dos Direitos Humanos a gestão de oito Secretarias Nacionais: Mulheres; Família; Criança e Adolescente; Juventude; Proteção Global; Igualdade Racial; Pessoa com Deficiência; e Pessoa Idosa.

Em pouco tempo a gestão de Damares marcou polêmicas advindas de suas declarações fortemente centradas no conservadorismo e familismo, ${ }^{19}$ mobilizando diversas mídias e a opinião pública. Dentre estas, vale destacar: “O Estado é laico, mas essa ministra é terrivelmente cristã" (VIVAS, 2019). Afirmou ainda que o Brasil entrava em "uma nova era em que menino veste azul e menina veste rosa" (PAINS, 2019). A proposta de abstinência sexual entre adolescentes como política pública para a prevenção de infecções sexualmente transmissíveis e gravidez precoce, medida sem amparo científico, aponta para o tratamento de uma questão de saúde pública fundamentada por princípios morais conservadores. Assim, a ministra camufla com ares científicos sua própria fé, querendo arrebanhar cidadãos de uma democracia, como se fosse "rebanho evangélico" (DINIZ; CARINO, 2020).

De acordo com Biroli (2020), há um aparelhamento do ministério por ativistas cristãos e conservadores com foco na implementação de políticas públicas para mulheres, crianças, adolescentes, jovens e idosos, substituindo o enfoque de gênero, em especial os direitos sexuais e reprodutivos, como eixo transversal de política pública, para assumir família como dimensão central.

\footnotetext{
17 Durante o governo Dilma, houve a fusão das Secretarias Especiais da Mulher, Igualdade Racial e Direitos Humanos, resultando no Ministério das Mulheres, da Igualdade Racial e dos Direitos Humanos (MMIRDH); extinto no governo Temer, "renasce" no governo Bolsonaro sob nova roupagem e uma orientação claramente familista, como veremos a diante.

18 Polêmica em decorrência da fala de Damares, que se autoatribuiu o título de mestrado, alegando que sua titulação se fundamenta biblicamente, com base em Efésios 4:11: "Ele designou alguns para apóstolos, outros para profetas, outros para evangelistas e outros para pastores e mestres". Disponivel em: https://www1.folha.uol.com.br/poder/2019/01/semdiploma-damares-ja-se-apresentou-como-mestre-em-educacao-e-direito.shtml. Acesso em: 8 fev. 2020.

${ }^{19}$ Entendemos "familismo" um traço e um qualificativo para um conjunto de políticas sociais orientadas à responsabilização das famílias pelos cuidados no âmbito privado, garantindo apoio a indivíduos somente quando não possuem lastro familiar (CARLOTO; NOGUEIRA, 2018; ESPING-ANDERSEN, 1999).
} 
Uma evidência disso foi o edital $02 / 2021,{ }^{20}$ lançado pela Coordenação de Aperfeiçoamento de Pessoal de Nível Superior (Capes) para o fomento de políticas públicas para a família, de modo a sustentar tais relações e ampliar sua capacidade de autonomia e responsabilização pela vida. Assim, a partir de recursos da Secretaria Nacional da Família/ MMFDH e da Capes, se constitui fomento de aproximadamente $\mathrm{R} \$ 2,5$ milhões, estratégia análoga a outras movimentações transnacionais da extrema-direita que objetiva referendar suas posições a partir da produção intelectual e valorização de novos pensadores, a exemplo da própria cúpula.

\section{Metodologia e análise}

Apesar das diferenças entre os governos que se sucederam no período democrático pós-1988, a escolha pelo discurso do governo Bolsonaro na cúpula como campo empírico de análise justifica-se por questões tanto de política interna, como de agenda internacional.

Em termos de política interna, o MMFDH tem sido estratégico para instituir a pauta conservadora, tanto pela mudança radical empenhada pela ministra Damares - com enfoque familista, moralizante e restritivo da concepção de saúde integral das mulheres - como pela transversalidade do MMFDH em relação às outras pastas governamentais, sobretudo com as agendas de gênero e raça (SHALDERS, 2020).

Em perspectiva internacional, tal discurso não só promove a adesão emblemática do Brasil ao neoconservadorismo, como também coloca o país enquanto um agente em busca de maior protagonismo na condução deste processo transnacional. À medida que tencionam legislar moralidade pública, atacam direitos, naturalizam desigualdades e colocam em xeque sistemas democráticos.

Enquanto percurso metodológico, partiu-se de uma pesquisa documental (GIL, 2008) e pesquisa on-line (FLICK, 2009) para verificar conteúdos e registros do encontro, sendo identificado o website $^{21}$ oficial da cúpula, com as gravações em vídeo dos principais momentos, discursos e apresentações dos expositores, dentre estes, o discurso de Damares. Além disso, o discurso também foi publicado no site do Ministério da Mulher, da Família e dos Direitos Humanos. ${ }^{22}$

De acordo com Foucault (1969/1997), o discurso possui uma materialidade própria, haja vista que constitui um ato, um dispositivo, uma instituição ou acontecimento, permitindo identificar ações e sujeitos. Nesse sentido, o discurso como objeto não se restringe à linguagem, mas se manifesta por meio dela, a partir de relações de poder, posições ideológicas e processos inconscientes (MELO, 2009).

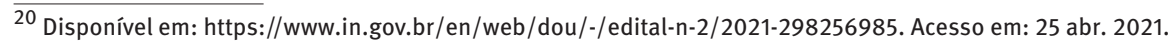

${ }^{21} \mathrm{O}$ website disponibiliza o conteúdo nas línguas húngara e inglesa.

${ }^{22}$ Disponível em: https://www.mdh.gov.br/todas-as-noticias/2019/setembro/na-hungria-ministra-damares-ressalta-queo-brasil-e-um-pais-pro-familia/DiscursoBudapeste.pdf. Acesso em: 5 set. 2019.
} 
Os discursos políticos guardam em si uma deliberação, uma vez que suas enunciações estabelecem um posicionamento, uma tomada de decisão. A partir da análise crítica do discurso (ACD), é possível desnaturalizar e tornar explícitas as relações de poder e disputas ideológicas que constituem os discursos. Importante destacar o caráter crítico desta perspectiva, que se coloca como um recurso para a agência de grupos oprimidos, de modo que possam influenciar na disputa pela prática social e questionamento da hegemonia (FAIRCLOUGH, 2001).

Para Fairclough e Fairclough (2012), a ACD se debruça sobre os argumentos práticos do discurso político, que buscam legitimar uma série de ações a serem executadas em uma dada leitura de realidade, para promover uma transformação social.

Dessa forma, a análise se organiza a partir de um quadro tridimensional, considerando o texto, a prática discursiva e a prática social (FAIRCLOUGH, 2001). Por ser uma abordagem eminentemente multidisciplinar, sua operacionalização se realiza e se acomoda conforme a formação e pelos conhecimentos sociológicos, linguísticos de psicologia e política de cada pesquisador.

\section{O discurso na III Cúpula Demográfica de Budapeste}

Ante a disponibilização das gravações dos discursos da III Cúpula, foi possível acessar o vídeo com o pronunciamento da ministra. 0 conteúdo de 11 minutos e 15 segundos estão distribuídos da seguinte forma: os primeiros dois minutos e 40 segundos são dedicados a uma fala improvisada e os demais oito minutos e 35 segundos trazem o discurso formal, previamente elaborado. Segundo Damares, este texto seria proferido pelo próprio presidente Bolsonaro.

Mediante o destaque e análise crítica do discurso do pronunciamento do governo, foi possível identificar recorrências e padrões discursivos. Em termos de análise linguística, verifica-se uma valorização do uso de palavras e termos que fazem referência a "população", "políticas públicas”, "família” e "gestões anteriores”. Nesse sentido, pode-se inferir que a população é vista como um grande objeto da ação estatal, passível de ser conduzida por intermédio de políticas públicas e que, a partir da gestão do governo Bolsonaro, terá outros rumos daqueles dados por gestões anteriores, sendo a família um campo simbólico no qual um conjunto de valores é imposto e determinante para configurar esses arranjos.

Durante a fala de improviso, observamos o Brasil sendo qualificado como uma "extraordinária nação”, detentora de diversidade linguística, étnica e cultural. Também está presente o enaltecimento da figura de Bolsonaro como um "incrível/grande líder", que a partir de ideais pró-família e pró-vida, chegou à Presidência para tirar o país de uma cenário de violência, levando-o ao crescimento e à paz.

O texto é composto por 15 parágrafos, de caráter dúbio, que a todo momento informa dados estatísticos e argumentos científicos, acompanhados de posicionamentos ideológicos, carregados de questões morais e polêmicas. 
O discurso abre com saudações à Hungria e elogios à organização do evento por sua relevância na questão demográfica. Dessa forma, ao enaltecer o nível da discussão em demografia, a gestão Bolsonaro busca legitimar o evento e respaldá-lo cientificamente, ainda que, dos 57 expositores da III Cúpula, apenas dois ${ }^{23}$ sejam representantes da comunidade científica, sendo ambos do próprio país anfitrião.

Em continuidade ao discurso, o governo traz dados e projeções demográficas que evidenciam o ápice da população brasileira em 2045/2050, havendo assim um bônus demográfico que deveria ser aproveitado pelo país, no sentido de acumular ativos e criar poupança para quando a transição demográfica se completar (TURRA, 2018; LEE; MASON, 2006). Damares então declara: “O governo brasileiro busca adaptar-se à nova realidade: uma de suas prioridades é a reforma da Previdência Social” (BRASIL, 2019). Aqui, a ministra associa a reforma da previdência como uma consequência óbvia e solução inequívoca para o cenário apresentado. Essa medida prioritária do governo busca implementar reformas ${ }^{24}$ no sistema de aposentadorias e pensões, reduzir os benefícios sociais e conter o custeio pelo orçamento público.

De acordo com Nulle e Moreira (2019), a partir de uma vigorosa análise da situação da Previdência Social e efeitos da Proposta de Emenda Constitucional 287/2016, o suposto déficit crescente no sistema previdenciário brasileiro pode ser questionado sob diversos aspectos constitucionais; mas especificamente com relação ao envelhecimento populacional, ajustes podem ser necessários. No entanto, o que está posto pelo governo Bolsonaro é uma modificação muito mais abrangente, que pode afetar a seguridade social como um todo, desconsiderando as desigualdades.

Alinhada ao contexto exposto pelo governo, a ministra declarou a reformulação ministerial como uma estratégia para o novo cenário demográfico, ao passo que sua pasta incorporou a Secretaria Nacional da Família e a Secretaria Nacional de Promoção e Defesa dos Direitos da Pessoa Idosa. “O foco especial na família pretende fortalecer sua estrutura e as relações intrafamiliares, sempre mantendo sua liberdade e autonomia [...] com atenção especial às famílias vulneráveis” (BRASIL, 2019).

De acordo com Miguel (2014), o sentido de família é um termo em disputa, haja vista que as configurações variam entre as sociedades humanas, ao longo dos tempos e de acordo com cada contexto, podendo se desenvolver em arranjos mais variados possíveis. Nesse sentido, quando se fala de família no singular, há uma valorização de uma determinada forma familiar.

Segundo Bruschini (1989), família em sua dimensão política é um arranjo que distribui papéis, ao mesmo tempo que constitui posições de privilégios, a partir da subordinação

\footnotetext{
${ }^{23}$ Representantes da comunidade científica com exposição durante a cúpula: Frank Füredi, professor emérito de sociologia da University of Kent e pesquisador sênior do XXI Century Institute de Budapeste; e Zsolt Spéder, demógrafo e diretor do Hungarian Demographic Research Institute e professor da University of Pécs na Hungria.

24 Em 22 de outubro de 2019, o Senado encerrou a última fase da aprovação da Reforma da Previdência (PEC 6/2019), sendo promulgada em 22 de novembro, com projeções de trazer redução de $\mathrm{R} \$ 800$ bilhões em despesas previdenciárias em dez anos.
} 
de outros integrantes. Sorj (2013) compila os diversos termos formulados pelos estudos feministas para nomear os papéis historicamente atribuídos às mulheres: "trabalho não pago", "trabalho não remunerado", "trabalho reprodutivo", "trabalho não mercantil”, etc. A família, enquanto resultado de decisões políticas e normatividade de relações de poder, consagra o poder masculino, sendo esta a causa de uma série de desigualdades de gênero (MIGUEL, 2014).

No trecho do discurso sobre família, é importante frisar o uso dos termos "liberdade" e "autonomia". A defesa da família foi um dos lemas da campanha de Bolsonaro. Com base nisso, se instituiu o combate à "ideologia de gênero", que tem implicado uma agenda contra "educação sexual", "gênero" 25 e "serviços de cuidado sexual e reprodutivo" em documentos oficiais, haja vista a atuação do Brasil na 41a Sessão Ordinária do Conselho de Direitos Humanos da ONU, buscando um alinhamento com países islâmicos em uma postura contrária ao universalismo dos direitos humanos e à postura histórica do Brasil de moderação e mediação em relação aos direitos reprodutivos (SAWYER, 2019).

Outro ponto do discurso que pode ser analisado é aquele que trata das políticas para a população idosa, um dos públicos-alvo do ministério chefiado por Damares:

Quanto aos direitos da pessoa idosa, além do exemplar programa de promoção do envelhecimento saudável, o governo tem buscado promover não apenas o bemestar material do idoso, mas também a solidariedade intergeracional como tributo e reconhecimento, e como fonte de aprendizado e experiência [...] proporcionar um ambiente familiar saudável, de modo a garantir um local seguro para as mulheres e crianças e para poder combater e prevenir a violência e a discriminação. (BRASIL, 2019)

O envelhecimento crescente da população e sua situação de vulnerabilidade muitas vezes requerem políticas públicas, especialmente entre as famílias que não têm recursos, ou entre os idosos sem familiares (CAMARANO, 2010). Porém, esses aspectos preocupantes são ignorados no delineamento da política que a ministra descreve, atribuindo à família a responsabilidade de cuidar de seus idosos, por meio da "solidariedade intergeracional”. Essa noção, inclusive, conflita com alguns princípios do próprio Sistema Único de Assistência Social (Suas), que garante assistência a pessoas em situação de vulnerabilidade (CRONEMBERGER; TEIXEIRA, 2015).

Buscando verificar a qual programa a ministra se refere, navegamos na temática "pessoa idosa" do site do governo, ${ }^{26}$ chegando ao "Programa Viver - Envelhecimento Ativo e Saudável”, ${ }^{27}$ instituído pelo Decreto n. 10.133 de 26/11/2019, ${ }^{28}$ em que constatamos, pela data de publicação do Decreto, que o programa surgiu oficialmente após o pronunciamento

\footnotetext{
25 O Itamaraty orienta diplomatas que gênero e sexo são sinônimos e não devem ser entendidos de maneira diferente, apagando a perspectiva cultural de gênero. Disponivel em: https://www1.folha.uol.com.br/colunas/maria-herminia-tavaresde-almeida/2019/06/deus-no-itamaraty.shtml. Acesso em: 25 jan. 2020.

${ }^{26}$ Disponivel em: https://www.gov.br/mdh/pt-br/navegue-por-temas/pessoa-idosa. Acesso em: 25 maio 2020.

27 Cartilha do Programa Viver - Envelhecimento Ativo e Saudável. Disponível em: https://www.mdh.gov.br/todas-asnoticias/2019/marco/ProgramaViver.pdf. Acesso em: 25 mar. 2020.

${ }^{28}$ Disponível em: http://www.planalto.gov.br/ccivil_03/_ato2019-2022/2019/decreto/D10133.htm. Acesso em: 25 jan. 2020.
} 
da ministra no evento em questão. Assim, o elogio público parece ser mais uma estratégia discursiva demagógica do que um argumento que qualifica uma política pública.

Ainda nesse trecho, cabe ressaltar duas expressões colocadas no discurso: a "solidariedade intergeracional” para um "ambiente familiar saudável”. Biroli (2020) reforça o quanto os cuidados pelas e dentro das famílias se convertem em solução prática em meio à precariedade da vida material. A concessão de direitos ou privilégios às famílias, em detrimento dos indivíduos, representa uma regulação institucional, o reforço de arranjo familiar como dispositivo de controle e de reprodução social das hierarquias, o que implica maior vulnerabilidade econômica, sobretudo para mulheres mais pobres (BIROLI, 2020). Por isso, Miguel (2014) alerta para a emergência de as relações de dependência e cuidados serem uma obrigação coletiva e social.

Aqui retomamos a questão da reforma da previdência, colocada anteriormente. Com o cenário de envelhecimento da população e com restrições aos ganhos previdenciários, restará às famílias o amparo social, promovendo assim a solidariedade intergeracional no caso das famílias mais pobres. Torna-se, portanto, explícito como as agendas neoliberais e conservadoras estão imbricadas, na medida em que a desarticulação de políticas públicas reforça as hierarquias tradicionais de classe, gênero e raça. Para Brown (2019), o neoliberalismo é um projeto político-moral, que busca minar a ação das políticas públicas promotoras de justiça social, acabando por agir em defesa das hierarquias tradicionais.

[...] privatização mercadológica da seguridade social, da saúde e do ensino superior envolveu a responsabilização de indivíduos masculinos, em vez do Estado, nos casos de gravidez na adolescência; dos pais, em vez do Estado, pelos custos da educação superior; e das famílias, em vez do Estado, pela provisão de qualquer tipo de cuidado para seus dependentes - sejam crianças, deficientes ou idosos. (WENDY, 2019, p. 20)

Na sequência de seu discurso, Damares diz:

Somos um país plural [...] uma enorme diversidade em todos os aspectos das nossas relações sociais. Não apenas respeitamos essa diversidade cultural, como nos orgulhamos dela. Isso não significa que não tenhamos muito a corrigir nas rotas e caminhos que vinham sendo trilhados pela nossa nação sob lideranças anteriores. (BRASIL, 2019)

No seu elogio à formação sociocultural do país, não há espaço para a descrição de uma realidade marcada por fortes discriminações, preconceitos e violências nas relações étnico-raciais. Contrariamente, a gestão da qual faz parte protagonizou situações de racismo e discriminação ao longo de todo processo eleitoral e durante o primeiro ano de governo.

Sem que se possa, por esse trecho somente, apontar uma concepção mais clara, é possível inferirmos, pelo posicionamento anterior de Bolsonaro e pela postura do presidente da Fundação Palmares, ${ }^{29}$ a constante negação de um racismo estrutural e um ensaio de

\footnotetext{
$\overline{29} 0$ presidente da Fundação Palmares, instituição pública voltada para a promoção da afrobrasilidade, em várias ocasiões não reconheceu a existência de racismo e chegou a debochar de figuras históricas ligadas às lutas antirracistas (cf. SERGIO CAMARGO..., 2020). Além disso, não só minimizou a existência do racismo no Brasil, como também afirmou que a escravidão foi benéfica aos seus descendentes (SANCHES, 2019).
} 
retorno a um entendimento anterior sobre o Brasil como uma “democracia racial”, na qual o preconceito seria localizado e não estruturante da sociedade brasileira (GUIMARÃES, 2006).

Nesse trecho, até então mais genérico, a maior relevância é evocar a necessidade de "corrigir rotas e caminhos", dando a entender que as políticas públicas relacionadas à diversidade, em termos de distribuição, reconhecimento e participação de parcelas minorizadas da população, devem mudar. Sem que sejam explicitadas, ficam subentendidas possíveis críticas às políticas de igualdade racial, diversidade sexual, etc., alvos constantes de críticas durante a campanha e governo. Entretanto, no discurso, os novos direcionamentos não são explicitados.

Na sequência, outro destaque diz respeito à segurança pública:

Um dos nossos principais desafios é o de resolver os nossos problemas relacionados com a segurança pública, que tem impedido um maior florescimento das nossas famílias e de nossos grandes potenciais humanos [...] nos primeiros seis meses do governo [...] já tivemos uma redução da ordem de $22 \%$ de mortes violentas, em comparação ao mesmo período do ano passado. (BRASIL, 2019).

Antes de mais nada, o dado por si só, no curto espaço de tempo, já impressiona a audiência pela eventual efetividade das medidas empreendidas pelo governo. Entretanto, de acordo com apuração do Projeto Comprova (2019), não é possível atribuir essa redução ao atual governo, haja vista que efeitos de políticas de segurança pública são perceptíveis a longo prazo, sendo os governos municipais e estaduais os maiores responsáveis. 0 Comprova ressalta ainda que as medidas que foram tomadas pelo governo federal, como flexibilização do acesso a armas, excludente de ilicitude que se associa a uma licença para matar e o endurecimento de penas, costumam ser contraproducentes em segurança pública.

Mais uma vez, o discurso retoma a questão da família e a criação de políticas voltadas ao seu fortalecimento: “criação de um Observatório da Família, que tem por finalidade coletar e compilar dados que nos permitam formular e executar, com base em evidências, sólidas políticas públicas para o enfrentamento dos problemas que afetam o bem-estar das famílias brasileiras" (BRASIL, 2019).

Nesse trecho, é utilizada uma estratégia de anunciar algo novo para fazer frente a desafios persistentes. 0 referido observatório, vinculado à Secretaria Nacional da Família, busca incentivar estudos e pesquisas na temática sobre família, tanto para fins de formulação de políticas públicas, como também para troca e difusão de conhecimento científico sobre família no mundo.

O mesmo governo que faz esta proposta é responsável por uma sucessão de ataques ao Censo Demográfico, referência para políticas públicas. De acordo com carta aberta da Associação Brasileira de Estudos Populacionais, o Censo previsto inicialmente para 2020 já tinha sofrido corte orçamentário em 2019 e, após ser adiado em razão da pandemia, sofreu novo corte em 2021, acumulando redução de $90 \%$ do valor previsto, o que levou inclusive à exoneração da presidenta do Instituto Brasileiro de Geografia e Estatística (IBGE), Susana Guerra, abrindo espaço para eventual aparelhamento de instituição (ABEP, 2021). 
Os ataques ao Censo representam uma ameaça para qualquer tipo de leitura sobre os diversos grupos etários, das relações de gênero e étnico-raciais, haja vista o potencial de comparação de dados que o estudo permite. Aqui, já se encontra uma contradição com base no pronunciamento de respeito à diversidade cultural, informado anteriormente. Assim, a tentativa de uma ancoragem de formulação e execução de política pública, renunciando um aparato censitário de alta credibilidade, parece ser mera estratégia discursiva para tentar convencer o público.

Nessa altura do discurso, seguindo uma abordagem familiar, se lança um olhar sobre a infância e Damares declara:

Não há como priorizar a família sem investir nas nossas crianças, respeitando sua integridade, tratando-as como crianças que são e dizendo um sonoro "NÃO" à ideologia de gênero. Trago, como exemplo, o nosso exitoso programa Criança Feliz [...] dando-lhes o devido encaminhamento nas áreas de nutrição, saúde e educação. (BRASIL, 2019)

Nessa argumentação em torno da atenção à infância, a “ideologia de gênero" é utilizada para desqualificar a introdução do trabalho pedagógico de gênero nos currículos escolares, posicionando estas abordagens como um ataque à integridade da criança, naturalizando assim as hierarquias e relações de poder. De acordo com Louro (1997), quando se trata das questões de gênero, historicamente desiguais, caberá à proposta pedagógica da escola reproduzir as assimetrias, discriminações e violências, ou atuar, então, a partir da desconstrução das relações de gênero.

Segundo Junqueira (2018), a “ideologia de gênero" é uma estratégia político-discursivo reacionária, de matriz religiosa, que avança nas alianças com amplos setores de maneira transnacional - políticos, juristas, jornalistas, lideranças escolares, psicólogos, médicos, eleitores, etc. - capaz de promover mobilizações da ordem moral ligadas às relações de gênero, sexo e sexualidade, se utilizando de "pânicos morais"30 (COHEN, 2011), com vistas a naturalizar as relações de gênero, se opondo à crítica feminista e aos direitos sexuais.

No encadeamento do discurso, após trazer à tona a infância, a fala se direciona para:

0 governo do presidente Bolsonaro, por sua vez, defende o direito à vida desde a concepção e condena a prática do aborto como método contraceptivo ou de controle de natalidade. O Sistema Único de Saúde (SUS) dá acesso universal ao atendimento pré-natal, provê assistência durante o parto e acompanhamento posterior, inclusive fornecendo acesso gratuito a vacinas e medicamentos. (BRASIL, 2019)

Aqui se verifica uma estratégia discursiva recorrente no argumento conservador contra direitos reprodutivos, que trata de legislar por uma vida intrauterina, em detrimento da autonomia e da vida das mulheres. Importante ressaltar que a fala destaca a cobertura de serviços de saúde para gestação, parto e, inclusive, imunização e medicação, como se

\footnotetext{
${ }^{30}$ Trata-se de formas de desaprovação ou condenação social a partir de histerias sociais desproporcionais a um determinado fenômeno social considerado como desvio, catalisado pela mídia. Seria, então, uma preocupação circunstancial em relação a uma ameaça, real ou imaginada, direcionada a um determinado grupo social responsabilizado pelo problema, que consensualmente com participação da mídia pode representar uma grande ameaça, na medida em que se exagera no número de casos ou na força de determinado fenômeno social (COHEN, 2011).
} 
fossem todas as condições necessárias e suficientes para garantir uma vida plena para crianças e mulheres.

Sorj (2013), em análise da legislação trabalhista, verifica que, na dupla condição de cuidado e trabalho, mulheres com trabalho formal encontram proteção apenas durante a fase reprodutiva e nos cuidados do bebê até seis meses de vida. No restante do ciclo de vida familiar, o único apoio que se dá é a licença de dois dias consecutivos em caso de falecimento de familiar próximo.

Caminhando para o fim, o discurso avança:

Frise-se que nosso governo não busca interferir na família, mas protegê-la, assegurando sua autonomia e liberdade. Nesse quadro, buscamos promover uma política de fortalecimento da maternidade e de incentivo à adoção, bem como prestar o necessário apoio às famílias uniparentais, geralmente chefiadas por mulheres, que são muito comuns no Brasil. (BRASIL, 2019)

Nesse trecho, se estabelece família como uma estrutura universal essencialmente produto da natureza. De acordo com Bruschini (1989), a antropologia, a partir de seus estudos clássicos, entende família como uma estrutura cultural, com configuração que varia em função das sociedades e dos diferentes períodos históricos. Ainda, de acordo com a autora, família seria então "um conjunto de pessoas ligadas por laços de sangue, parentesco ou dependência, que estabelecem entre si relações de solidariedade e tensão, conflito e afeto" (BRUSCHINI, 1989, p. 13).

De todas as formas, remeter a família ao âmbito do natural não é um mero desconhecimento dos estudos culturais e de gênero, mas sim parte de um dispositivo político-discursivo. De acordo com Junqueira (2018), trata-se de uma "guerra cultural” reacionária que busca retomar a ordem social para o âmbito natural e da tradição moral, a partir da aliança de diversos setores sociais, com mobilização popular a partir de pânicos morais como forma de enfrentar a igualdade de gênero e os direitos sexuais e reprodutivos conquistados nas últimas décadas.

Finalmente, o discurso se encerra com um chamamento para um ativismo global:

[...] convidar todos os Estados aqui representados para juntar-se a nós na formação de um grupo de países amigos de família, para, no âmbito da Organização das Nações Unidas, defender e resgatar os valores que alguns setores tendem, muitas vezes, a ignorar. (BRASIL, 2019)

Este chamamento ao final do discurso coloca o Brasil em um lugar de construção de uma liderança em uma aliança global neoconservadora, com desdobramentos para diversos campos políticos internacionais e de agendas nacionais. De acordo com Biroli (2020), essa reação é construída por uma ampla aliança entre neoliberais e conservadores, constituída em contextos democráticos, que tem conseguido associar as crises sociais e econômicas a uma disfunção moral das famílias, ou seja, à chamada "moralização das inseguranças", como um tipo de política neoconservadora. 
De acordo com Junqueira (2018), essa política busca recuperar e garantir a existência de hierarquias sexuais para o fortalecimento de visões de mundo tradicionais, a serem manifestadas em um conjunto cultural bastante específico, tal como: um único modelo de família (patriarcal, biológica, monogâmica, heterossexual, via matrimônio, indissolúvel e filhos), matrimônio (comunhão de vida e amor conjugal), maternidade (inerente à mulher, sendo mãe, esposa, submissa, afetuosa e dedicada a cuidados), filiação (estabelecida por via biológica, com conjugalidade complementar), parentesco (consanguinidade), sexo (como um dado biológico que permita reprodução), sexualidade (como complementar), heterossexualidade (desejo sexual natural e universal), identidade e diferença sexual (sendo fixas, binárias e hierarquizadas).

Assim, ao analisarmos o recente histórico diplomático entre os governos de Orbán e de Bolsonaro, juntamente com os diversos episódios contrários às pautas de gênero e implementação de políticas reacionárias, não se pode subestimar o papel que as Cúpulas Demográficas de Budapeste podem ter na articulação e ascensão de novas pautas e implementação de políticas articuladas em diversos países, tomando por base a releitura da questão demográfica sob nova ótica - da eugenia, xenofobia, nacionalismo e familismo.

Forças da extrema-direita conservadora se articulam mundialmente e têm fincado sólidas raízes no Brasil, comprometidas com uma verdadeira revolução cultural, redefinindo ideias e valores e mudando as relações no interior da sociedade, como afirmou recentemente o filósofo Vladimir Safatle (BARROCAL, 2020). Como disse a ministra, em reunião ministerial: "eu preciso fazer sempre isso pra que a gente não perca o foco. A questão de valores, ministro” (DITEC, 2020).

\section{Considerações finais}

A partir da análise empreendida, foi possível constatar a guinada operada pelo Brasil - com o governo Bolsonaro -, fortalecendo relações com um país com o qual antes mantinha relações insignificantes, passando a visitá-lo com frequência e participando da Cúpula Demográfica de Budapeste. Ainda que de pequena monta, o evento vem ganhando importância e ambiciona influenciar um número cada vez maior de países que rezem pela sua cartilha cristã, ocidental e conservadora. A participação do Brasil na cúpula é a marca evidente de uma inflexão do país à atual onda neoconservadora de âmbito internacional, se associando a governos de extrema-direita, fundamentalistas e contrários à defesa dos direitos humanos.

Com o uso de dados reais, projeções estatísticas e palavras vagas, procura-se alcançar uma audiência medianamente informada sobre a realidade nacional, ou qualquer pessoa bem-intencionada. Dessa forma, a estratégia discursiva apresenta a posição ideológica de seu governo, que é, na verdade, polêmica e com adesão seletiva por parte da população, tal como acontece nos casos da reforma da previdência, da centralidade na família para 
promoção de políticas públicas, da negação ao trabalho de gênero e sexualidade nas escolas e do aborto.

A participação do governo brasileiro sem discussão prévia ou integração com a sociedade civil e acadêmica na delegação dessa cúpula marca, por outro lado, uma inflexão ao que justamente possibilitou protagonismo do Brasil a partir da CIPD do Cairo, em que tais articulações trouxeram identidade histórica aos posicionamentos nacionais durante a série de conferências realizadas pela ONU.

Assim, o pronunciamento oficial da representante do governo se constrói a partir de posições sobre direitos sexuais e reprodutivos, noções de família e redefinições sobre perspectivas demográficas. 0 embate se dá, portanto, no campo da sociedade, da política, dos valores e da ciência. 0 chamamento para liderar um ativismo global nos espaços da ONU estabelece a marca do governo para um obscurantismo reacionário, bem como o compromisso com uma articulação em escala global que reivindica a reconstrução da realidade social, fortemente marcada pela reelaboração de princípios morais conservadores.

0 discurso analisado, antes de ser um fim, pode ser entendido como uma abertura de ampla agenda de pesquisa, na medida em que alude a um modelo de reprodução societal, com profunda articulação entre Estado, financeirização da economia, direitos, família, gênero, raça e subjetividades.

\section{Referências}

ARIES, Q. Season 8 - Democracy Undone. Episode 4: Rewriting History in Hungary. The Groundtruth Project. Roteiro: Quentin Aires. [s.i], 2019. (3 min.). Disponivel em: https:// thegroundtruthproject.org/rewrite-history-hungary-viktor-orban/. Acesso em: 15 fev. 2020.

ABEP - Associação Brasileira de Estudos Populacionais. Carta aberta em defesa do IBGE e do Censo. 2021. Disponível em: http://www.abep.org.br/site/index.php/noticias/1921-carta-abertaem-defesa-do-ibge-e-do-censo. Acesso em: 15 abr. 2021.

BARROCAL, A. Bolsonaro se vê à frente de uma revolução em marcha e não vai parar. Carta Capital, 27 abr. 2020. Disponível em: https://www.cartacapital.com.br/politica/bolsonaro-seve-a-frente-de-uma-revolucao-em-marcha-e-nao-vai-parar/. Acesso em: 20 maio 2020.

BERQUÓ, E. As posições da OMS nas conferências de população da ONU nos últimos 50 anos. In: WONG, L. R. et al. Cairo+20: perspectivas de la agenda de población y desarrollo sostenible después de 2014. Rio de Janeiro: Alap, 2014. p. 17-22.

BIROLI, F. Gênero, neoconservadorismo e democracia: disputas e retrocessos na América Latina. São Paulo: Boitempo, 2020.

BRASIL. Ministério da Mulher, da Família e dos Direitos Humanos. Discurso por ocasião da III Cúpula Demográfica de Budapeste. Brasília, 2019. Disponível em: https://www.mdh.gov.br/ todas-as-noticias/2019/setembro/na-hungria-ministra-damares-ressalta-que-o-brasil-e-umpais-pro-familia/DiscursoBudapeste.pdf. Acesso em: 5 set. 2019.

BROWN, W. Nas ruínas do neoliberalismo. São Paulo: Editora Filosófica Politeia, 2019.

BRUSCHINI, C. Uma abordagem sociológica de família. Revista Brasileira de Estudos de População, São Paulo, v. 6, n. 1, jan./jun. 1989. 
BRUSCHINI, C.; RICOLDI, A. Articulação, trabalho e família: famílias urbanas de baixa renda e políticas de apoio às trabalhadoras. São Paulo: Fundação Carlos Chagas, 2008 (Textos FCC, v. 28).

CAMARANO, A. A. Cuidados de longa duração para a população idosa: um novo risco social a ser assumido? Rio de Janeiro: Ipea, 2010.

CARLOTO, C.; NOGUEIRA, B. Família, gênero e proteção social. Revista em Pauta, Rio de Janeiro, v. 16, n. 42, p. 49-64, 2018.

CHADE, J. Extrema-direita húngara quer Brasil financiando cristãos no Oriente Médio. Uol, São Paulo, 27 nov. 2019. Disponível em: https://noticias.uol.com.br/colunas/jamilchade/2019/11/27/extrema-direita-hungara-quer-brasil-financiando-cristaos-no-oriente-medio. htm. Acesso em: 20 fev. 2020.

COHEN, S. Folk devils and moral panics: the creation of the Mods and Rockers. London: Routledge Classics, 2011.

CORREA, S. A "política do gênero": um comentário genealógico. Cadernos Pagu, Campinas, n. 53, p. 1-16, jun. 2018.

CRONEMBERGER, I.; TEIXEIRA, S. O sistema de proteção social brasileiro, política de assistência social e a atenção à família. Pensando Famílias, Porto Alegre, n. 2, 2015.

DINIZ, D.; CARINO, G. A mentira da "preservação sexual” da ministra Damares: há correlação entre defesa da abstinência e o aumento da gravidez na adolescência e da maternidade precoce, apontam estudos. El País Brasil, São Paulo, 6 jan. 2020. Disponível em: https:// brasil.elpais.com/opiniao/2020-01-06/a-mentira-da-preservacao-sexual-da-ministra-damares. html?outputType=amp\&_t\%E2\%80\%A6. Acesso em: 31 jan. 2020.

DITEC. INSTITUTO NACIONAL DE CRIMINALÍSTICA. Laudo n. 1242/2020 - INC/DITEC/PF. Laudo de perícia criminal federal. Disponível em: https://pdfhost.io/v/FEN3nHBd._Agencia_Brasil_ laudo_Bolsonaro.pdf. Acesso em: 23 maio 2020.

ESPING-ANDERSEN, G. Social foundations of postindustrial economies. Oxford: Oxford University Press, 1999.

FAIRCLOUGH, N. Discurso e mudança social. Brasília: Editora Universidade de Brasília, 2001.

FAIRCLOUGH, I.; FAIRCLOUGH, N. Political discourse analysis: a method for advanced studies. London: Routledge, 2012.

FERREIRA, S. Orgulho e preconceito: a resposta europeia à crise de refugiados. Relações Internacionais, Lisboa, v. 50, n. 1, p. 87-107, jun. 2016.

FLICK, U. Métodos de pesquisa: introdução à pesquisa qualitativa. Porto Alegre: Penso Editora, 2009.

FOUCAULT, M. Arqueologia do saber. Rio de Janeiro: Forense, 1997. (Obra original publicada em 1969).

GIL, A. C. Métodos e técnicas de pesquisa social. São Paulo: Atlas, 2008.

GUIMARÃES, A. S. Depois da democracia racial. Tempo Social, v. 18, n. 2, nov. 2006.

JUNQUEIRA, R. A invenção da "ideologia de gênero": a emergência de um cenário político-discursivo e a elaboração de uma retórica reacionária antigênero. Psicologia Política, Porto Alegre, v. 18, n. 43, set./dez. 2018.

LEE, R.; MASON, A. What is the demographic dividend? Finance \& Development, IMF, v. 43, n. 3, 2006. 
LOURO, G. Gênero, sexualidade e educação: uma perspectiva pós-estruturalista. Petrópolis: Vozes, 1997.

MACHADO, L. Z. O aborto como direito e o aborto como crime: o retrocesso neoconservador. Cadernos Pagu, Campinas, n. 50, p. 1-48, jul. 2017.

MIGUEL, L. F. Feminismo e política: uma introdução. São Paulo: Boitempo, 2014.

MELO, I. Análise do discurso e análise crítica do discurso: desdobramento e intersecções. Letra Magna, ano 5, n. 11, p. 1-18, dez. 2009.

MARTINS, R. Do Cairo a Nairóbi: 25 anos da agenda de população e desenvolvimento no Brasil. Revista Brasileira de Estudos de População, São Paulo, v. 36, p. 1-9, dez. 2019.

NULLE, A. L.; MOREIRA, C. S. A Previdência Social: reforma ou há alternativas? Economia e Sociedade, Campinas, v. 28, n. 3, p. 791-819, dez. 2019.

PAINS, C. "Menino veste azul e menina veste rosa”, diz Damares Alves em vídeo. 0 Globo, Rio de Janeiro, 3 jan. 2019. Sociedade. Disponível em: https://oglobo.globo.com/sociedade/meninoveste-azul-menina-veste-rosa-diz-damares-alves-em-video-23343024. Acesso em: 22 fev. 2020.

PROJETO COMPROVA. Com dados fora de contexto, publicação atribui a Bolsonaro sucesso em índices de segurança. Estadão, São Paulo, 10 out. 2019. Estadão Verifica. Disponível em: https:// politica.estadao.com.br/blogs/estadao-verifica/com-dados-fora-de-contexto-publicacaoatribui-a-bolsonaro-sucesso-em-indices-de-seguranca/. Acesso em: 29 fev. 2020.

TURRA, C. Os ajustes inevitáveis da transição demográfica no Brasil. In: VIEGAS, M.; ALBUQUERQUE, E. Alternativas para uma crise de múltiplas dimensões. Belo Horizonte: Cedeplar - UFMG, 2018.

RODRIGUES, R. Na ONU, Brasil promove desmonte de política progressista de direitos humanos. Gênero e Número, 19/09/2019. Disponível em: http://www.generonumero.media/onu-brasilconservadorismo-direitos-humanos/. Acesso em: 25 abr. 2021.

SANCHES, M. Novo presidente da Fundação Palmares minimiza racismo no Brasil em post; entidades criticam. G1, Brasília, 28 nov. 2019. Disponível em: https://g1.globo.com/rj/rio-dejaneiro/noticia/2019/11/28/novo-presidente-da-fundacao-palmares-minimiza-racismo-nobrasil-em-post.ghtml. Acesso em: 20 maio 2020.

SARDENBERG, C. Negociando gênero em desenvolvimento: os feminismos brasileiros em destaque. Cadernos Pagu, Campinas, n. 52, p. 1-46, nov. 2018.

SCOTT, J. Prefácio a Gender and Politics of History. Cadernos Pagu, Campinas, n. 3, p. 11-27, 2007.

SCOTT, J. Gênero: uma categoria útil de análise histórica. Educação \& Realidade, Porto Alegre, v. 2, n. 20, p. 71-100, jul./dez. 1995.

SERGIO CAMARGO, presidente da Fundação Palmares, chama movimento negro de 'escória maldita' em reunião. G1, 2/6/2020. Disponível em: https://g1.globo.com/politica/ noticia/2020/06/02/sergio-camargo-presidente-da-fundacao-palmares-chama-movimentonegro-de-escoria-maldita-em-reuniao.ghtml. Acesso em: 24 abr. 2021.

SHALDERS, A. Como Damares Alves saiu de ministra 'periférica' a figura central do bolsonarismo. BBC News Brasil, 3 set. 2020. Disponivel em: https://www.bbc.com/portuguese/brasil-53980530. Acesso em: 24 ago. 2020.

SORJ, B. Arenas de cuidado nas interseções entre gênero e classe social no Brasil. Cadernos de Pesquisa, São Paulo, v. 43, n. 149, p. 478-491, maio/ago. 2013. 
SAWYER, D. Palco e bastidores da Conferência Internacional sobre População e Desenvolvimento. Revista Brasileira de Estudos de População, São Paulo, v. 36, p. 1-8, dez. 2019.

VIVAS, F. 'Estado é laico, mas esta ministra é terrivelmente cristã': diz Damares ao assumir Direitos Humanos. G1, Política, Brasília, 2 jan. 2019. Disponível em: https://g1.globo.com/politica/ noticia/2019/01/02/estado-e-laico-mas-esta-ministra-e-terrivelmente-crista-diz-damares-aoassumir-direitos-humanos.ghtml. Acesso em: 15 jan. 2020.

\section{Agradecimentos}

A escrita é um ato coletivo que congrega múltiplas relações e acúmulos ao longo da vida. Para esse artigo os agradecimentos são, em especial, à generosidade de Melissa Suarez pelas conversas que permitiram uma aproximação com a análise linguística, a Maíra Teixeira da Silva pela atenta revisão textual e ao grupo de estudos Resistências - Controle Social, Memória e Interseccionalidades (UFABC) pelas reflexões durante o processo de avaliação do artigo.

\section{Sobre os autores}

Felipe Furini Soares é mestrando em Ciências Humanas e Sociais pela Universidade Federal do ABC. Professor de Sociologia no colégio da Universidade Municipal de São Caetano do Sul (USCS).

Arlene Martinez Ricoldi é doutora em Sociologia pela Universidade de São Paulo (USP). Professora adjunta da Universidade Federal do ABC, credenciada nos Bacharelados em Ciências e Humanidades e Políticas Públicas. Coordenadora do Programa de Pós-Graduação em Ciências Humanas e Sociais da UFABC. Integrante do Comitê de Ética em Pesquisa.

\section{Endereço para correspondência}

Felipe Furini Soares

Universidade Federal do ABC

Alameda da Universidade, sala 374, bloco Delta, $3^{\circ}$ andar, Bairro Anchieta 09606-045 - São Bernardo do Campo-SP, Brasil

Arlene Martinez Ricoldi

Universidade Federal do ABC

Alameda da Universidade, sala 374, bloco Delta, $3^{\circ}$ andar, Bairro Anchieta

09606-045 - São Bernardo do Campo-SP, Brasil 


\section{Abstract}

Neoconservative escalation and the anti-gender agenda: the case of Brazil's participation in the Budapest Demographic Summit

This article seeks to analyze the significance of Brazil's participation in the 3rd Budapest Demographic Summit. This meeting follows a series of events that have taken place since 2015, through the rise of Viktor Orbán's extreme right-wing administration. Seeking to tackle population decline, based on anti-immigration and pro-family strategies, the event has been positioning itself as a counterpoint to the UN Conferences. To that end, we began an online and documentary research on the website of Summit organizers and the Brazilian government, followed by a Critical Discourse Analysis (ACD) of the speech by Minister Damares Alves during the event, with reflections from post-structuralist feminist studies. A clear inflection to the global neoconservative and anti-gender agenda is observed in Brazil through the association with far-right countries, opposed to the defense of Human Rights, and fundamentalists. The speech included instrumentalized demographic notions used to camouflage ideological perspectives in relation to gender and launch attacks on sexual and reproductive rights and to non-traditional notions of family disguised as scientific discourse.

Keywords: Gender. Family. Demographic. Budapest Summit. Bolsonaro’s government.

\section{Resumen}

Escalada neoconservadora y agenda antigénero: el caso de la participación de Brasil en la Cumbre Demográfica de Budapest

Este artículo busca analizar el significado de la participación de Brasil en la III Cumbre Demográfica de Budapest. Esta reunión deriva de una serie de eventos que han tenido lugar desde 2015, con el surgimiento del gobierno de extrema derecha de Viktor Orbán. Con el objetivo de pensar en enfrentar el declive de la población, basado en estrategias antiinmigración y profamilia, el evento se ha posicionado como un contrapunto a las conferencias de la ONU. Como camino metodológico, comenzamos con una investigación documental y en línea en el sitio web de los organizadores de la cumbre y del gobierno brasileño, para luego utilizar el análisis crítico del discurso para la declaración de la ministra Damares Alves durante el evento, con la reflexión de los estudios feministas posestructuralistas. Lo que está claro es una inflexión de Brasil hacia la agenda global neoconservadora y antigénero, para la que se asocia con países de extrema derecha, fundamentalistas y opuestos a la defensa de los derechos humanos. El discurso analizado instrumentaliza las nociones demográficas para camuflar sus perspectivas ideológicas en relación con el género, y les da un aire de discurso científico a los ataques a los derechos sexuales y reproductivos y a las nociones no tradicionales de familia.

Palabras clave: Género. Familia. Demografía. Cumbre de Budapest. Gobierno de Bolsonaro.

Recebido para publicação em 01/06/2020 Aceito para publicação em 08/09/2021 